\title{
Infecções bacterianas pioram o prognóstico da hepatite alcoólica
}

\author{
Alcoholic hepatitis: bad prognosis due to concomitant \\ bacterial infections
}

\author{
Edna Strauss $^{1}$ e José Pedro Aerosa ${ }^{1}$
}

\begin{abstract}
RESUM0
As infecções bacterianas cursam com altos índices de morbilidade e mortalidade na cirrose hepática. O objetivo do nosso trabalho foi avaliar se também na hepatite alcoólica as infecções bacterianas são fatores de mau prognóstico. Na avaliação retrospectiva de 681 pacientes hospitalizados em um único centro, por período de 6 anos, foram bem documentados 52 (7,5\%) casos de hepatite alcoólica, sendo 73,1\% com biópsia hepática para análise histopatológica e os restantes por diagnóstico clínico-bioquímico. Houve predomínio do sexo masculino (relação 3,3:1,0), com idade média de 40 anos eingestão média de etanol puro de 193g/dia por mais de 3 anos. As principais complicações foram: encefalopatia hepática $(n=5)$, insuficiência renal $(n=4)$ e hemorragia digestiva alta $(n=3)$. Houveinfecção bacteriana em $11(21,1 \%)$ pacientes, sendo pulmonar $(n=5)$, peritonite bacteriana espontânea (PBE) $(n=2)$, urinária $(n=3)$ e dermatológica $(n=1)$. Óbito precoce, durante o período de internação ocorreu em $8(15,4 \%)$ casos e a análise comparativa entre eles e os sobreviventes mostrou serem fatores de mau prognóstico a presença de encefalopatia hepática ( $p=0,012)$, bilirrubinas > 20mg\% ( $p=0,012)$ e associação com infecções graves ( pulmonar/PBE), com p=0,004. Em conclusão, demonstramos que as infecções bacterianas são fatores de mau prognóstico na hepatite alcoólica. Recomendamos, portanto, que a profilaxia com antibióticos que se faz durante hemorragia digestiva alta na cirrose e em casos de insuficiência hepática fulminante, seja estendida para a hepatite alcoólica, em sua forma grave, com finalidade de evitar infecções bacterianas e mortalidade precoce.
\end{abstract}

Palavras-chaves: Hepatite alcoólica. Alcoolismo crônico. Cirrose hepática. Infecção pulmonar. Peritonite bacteriana espontânea. Prognóstico.

\begin{abstract}
Bacterial infections increase morbidity and mortality in cirrhosis. Our aim was to investigate whether in alcoholic hepatitis the development of bacterial infections was also a poor prognostic factor. In the retrospective evaluation of 681 hospitalized patients with liver disease, from a single center during a six-year period, 52 (7.5\%) cases of alcoholic hepatitis were well documented, 73.1\% by liver biopsy with histopathological analysis and the others by well characterized clinical-biochemical data. Males were predominant (ratio 3.3:1.0), mean age of 40 years and mean alcohol intake of 193g/day. Major complications were: Hepatic encephalopathy $(n=5)$, renal insufficiency $(n=4)$ and digestive bleeding $(n=3)$. Bacterial infections were found in $11(21 \%)$ patients, distributed into: pulmonary $(n=5)$, spontaneous bacterial peritonitis $(n=2)$, urinary $(n=3)$ and dermatological $(n=1)$. Early hospital death occurred in eight (15.4\%) patients and comparative analysis between these and those who survived showed that poor prognostic factors were: presence of hepatic encephalopathy $(\mathrm{p}=0.012)$, total bilirubin $>20 \mathrm{mg} \%(\mathrm{p}=0.012)$ and the presence of severe infections (pulmonary and spontaneous bacterial peritonitis) with statistical significance $(\mathrm{p}=0.004)$. In conclusion we have demonstrated that severe bacterial infections are poor prognostic factors for alcoholic hepatitis. Our recommendation, based on prophylaxis with antibiotics during digestive bleeding in cirrhosis and in acute hepatic insufficiency, is to extend this prophylaxis to alcoholic hepatitis, in its severe form, in order to prevent bacterial infections and early death.
\end{abstract}

Key-words: Alcoholic hepatitis. Chronic alcoholism. Hepatic cirrhosis. Pulmonary infection. Spontaneous bacterial peritonitis. Prognosis.

1. Clínica de Gastroenterologia do Hospital Heliópolis, São Paulo, SP.

Endereço para correspondência: Dra. Edna Strauss. R. Flórida 169/91, 04565-000 São Paulo, SP

Tel: 11 3061-5549 ramal 360

e-mail: edna.strauss@ honet.usp.br

Recebido para publicação em 9/7/2003

Aceito em 15/4/2004 
A doença hepática alcóolica costuma apresentar-se clinicamente dentro de um amplo espectro que vai desde esteatose leve até cirrose hepática descompensada. Os mecanismos fisiopatológicos para a progressão da doença não estão totalmente elucidados, porém se aceita que 0 surgimento de processo inflamatório intenso e fibrose peri-sinusoidal/pericentral, caracterizando hepatite alcoólica é etapa importante neste processo evolutivo?.

A hepatite alcóolica tanto pode instalar-se em fígado não cirrótico como pode estar superposta em pacientes com arquitetura hepática alterada pela formação de nódulos de regeneração envoltos em fibrose ${ }^{8}$. 0 quadro clínico de hepatite alcóolica pode ser leve ou intenso, independentemente do substrato anatômico inicial, sendo relatados altos índices de mortalidade. Face o diagnóstico clínico de hepatite alcóolica, alguns parâmetros tem sido referidos como índices de mau prognóstico, entendidos como evolução para o óbito, entre eles a presença de encefalopatia hepática ( $E H)$, níveis de bilirrubinas totais $>20 \mathrm{mg} \%$.

Por outro lado, o estudo das infecções bacterianas associadas às doenças hepáticas vem apresentando crescente interesse nos últimos anos ${ }^{4}{ }^{21}$. A infecção do liquido ascítico - peritonite bacteriana espontânea - pode ocorrer com ausência de sinais clínicos clássicos tipo febre e leucocitose, sendo diagnosticada por resultados laboratoriais específicos como numero de neutrófilos $>250 / \mathrm{mm}^{3}$ no líquido ascític ${ }^{14}$. Recentemente, também a infecção do liquido pleural e a bacteremia ( positividade das hemoculturas) são valorizadas por caracterizar infecções bacterianas espontâneas ${ }^{22}$. A detecção de infecção e seu imediato tratamento especifico com antibióticos reconhecidamente eficazes tem possibilitado a diminuição significativa dos índices de mortalidade nos episódios de peritonite bacteriana espontânea ${ }^{19}$.

Pior prognóstico ou índices aumentados tanto de morbidade como de mortalidade nos pacientes com infecções bacterianas estão plenamente demonstrados na cirrose ${ }^{346}$. De forma semelhante, na insuficiência hepática aguda ${ }^{13} \mathrm{e}$ durante episódios de hemorragia digestiva alta ( $\mathrm{HDA}$ ) por hipertensão portal ${ }^{216}$, a presença de infecções bacterianas agravam sobremaneira 0 prognostico dos pacientes.

A busca sistemática de processos infecciosos em doença hepática tem sido rotina em nosso Serviço, o que possibilitou revisarmos nossa casuística de hepatite alcóolica, com finalidade de avaliar se a presença de infecções bacterianas seria mais um entre os fatores de pior prognostico desta grave condição clinica.

\section{PACIENTES E MÉTODOS}

Durante período de 6 anos foram internados na Clínica de Gastroenterologia do Hospital Heliópolis 681 pacientes com doença hepática. Deste universo houve confirmação de hepatite alcóolica em 52 pacientes. Na avaliação retrospectiva desses casos coletamos dados como sexo, idade, tempo de internação e ingestão alcóolica. Os sinais e sintomas pesquisados foram febre, astenia, anorexia, icterícia, colúria, emagrecimento, ascite, hepatomegalia, aranhas vasculares e eritema palmar. Niveis séricos de bilirrubinas totais e de enzimas hepáticas: alanina-aminotransferase (ALT), aspartatoaminotransferase (AST), gama-glutamil-transpeptidase (GGT) foram analisados assim como a atividade da protrombina (\%), níveis séricos de albumina e creatinina e contagem total de leucócitos nos sangue periférico.

0 diagnóstico de hepatite alcóolica foi confirmado por biópsia hepática em 38 (73,1\%) pacientes. Na impossibilidade de avaliação histopatológica do fígado, devido fundamentalmente ao grande alargamento do tempo de protrombina, fizemos 0 diagnóstico através de dados clínicos e bioquímicos. Entre os dados clínicos destacam-se a ingestão alcoólica recente e dor abdominal com hepatomegalia, mais raramente acompanhada por astenia, anemia e icterícia. Nos exames laboratoriais chama a atenção a leucocitose com desvio à esquerda, na ausência de processo infeccioso. 0 surgimento de complicações como encefalopatia hepática, hemorragia digestiva alta ou insuficiência renal foram registrados.

Foi considerado alcoolista crônico o indivíduo que consumiu por mais de 3 anos quantidades superiores a 60 gramas de etanol puro por dia para 0 homem e 40 gramas para a mulher. Para 0 diagnóstico de infecções bacterianas, quando da internação do paciente ou no surgimento de sinais suspeitos ou complicações, foram realizados Rx de tórax, tipo I de urina, urocultura e hemoculturas (2 ou 3 amostras). Nos pacientes com ascite 0 diagnostico de perinotine bacteriana espontânea foi realizado pela presença de polimorfonucleares neutrófilos $>250 / \mathrm{mm}^{3} \mathrm{com}$ ou sem 0 crescimento de um germe na cultura do liquido ascítico. Para o diagnóstico de infecção urinária foram considerados tanto os casos com cultura positiva como aqueles com leucocituria $\left(>60.000 / \mathrm{mm}^{3}\right)$ e nas infecçoes pulmonares os exames de imagem ( Rx de tórax), associados ou não à positividade de hemoculturas.

A análise estatística para comparação dos índices de mortalidade entre os pacientes com ou sem o fator de mau prognóstico em estudo foi feita pelo teste exato de Fisher, considerando 0 nível de significância de 5\%.

\section{RESULTAD0S}

A prevalência de hepatite alcóolica correspondeu a 7,5\% de todos os casos hospitalizados por doença hepática. Os dados gerais desta casuística estão na Tabela 1.

Tabela 1 - Dados demográficos de 52 pacientes com hepatite alcoólica.

\begin{tabular}{lr}
\hline Sexo & \\
masculino & 40 \\
feminino & 12 \\
Idade (anos) & \\
$\quad$ média & $40 \pm 2,6$ \\
$\quad$ extremos & $19-69$ \\
Ingestão álcool ( $\mathrm{g} / \mathrm{d}$ ) & \\
$\quad$ média & $193 \pm 47$ \\
$\quad$ extremos & $52-600$ \\
Tempo internação (dias) & \\
$\quad$ média & 20 \\
extremos & $3-62$ \\
\hline
\end{tabular}


Os principais sinais e sintomas na apresentação da hepatite alcóolica estão listados na Tabela 2, destacando-se em primeiro lugar a hepatomegalia dolorosa (92,3\%). Entre as complicações na evolução clínica a ascite foi a mais freqüente e a hipertermia surgiu em oito pacientes. Alem das infecções bacterianas, outras complicações graves foram a encefalopatia hepática ( 5 casos), insuficiência renal ( 4 casos) e hemorragia digestiva alta ( 3 casos) .

Tabela 2 - Principaissintomas esinaisna apresentação da hepatitealcoólica e complicações durante sua evolução.

\begin{tabular}{lrr}
\hline & Número & Porcentagem \\
\hline Sintomas e sinais & & \\
hepatomegalia dolorosa & 48 & 92,3 \\
icterícia & 41 & 78,8 \\
colúria & 38 & 73,1 \\
anorexia & 38 & 73,1 \\
astenia & 37 & 71,1 \\
emagrecimento & 30 & 57,7 \\
aranhas vasculares & 33 & 63,4 \\
eritema palmar & 25 & 48,1 \\
Complicações & & \\
ascite & 17 & 32,7 \\
hipertermia & 8 & 15,4 \\
encefalopatia hepática & 5 & 9,6 \\
insuficiência renal (creatinina $>$ 3mg\%) & 4,7 \\
hemorragia digestiva alta & 3 & 5,7 \\
infecções bacterianas & 11 & 21,1 \\
\hline
\end{tabular}

Entre os exames complementares é importante destacar que a relação AST/ALT sempre foi maior do que 1, ou seja, os níveis da aspartato-aminotransferase estiveram sempre superiores aos da alanina-aminotransferase. 0 nível médio de AST foi de 3,6 vezes 0 valor normal enquanto o nível médio de ALT foi de duas vezes 0 valor máximo normal. Avaliação semiquantitativa das outras alterações laboratoriais estão apresentadas na Tabela 3.

A prevalência de infecções bacterianas nos pacientes com hepatite alcoólica foi de 21\% (11/52), assim distribuídas: infecção pulmonar $=5$ casos, peritonite bacteriana espontânea = 2 casos, infecção urinaria = 3 casos e infecção dermatológica ( erisipela) $=1$ caso .
A mortalidade global entre os pacientes com hepatite alcóolica foi de 15,4\% ( 8 casos). A comparação dos parâmetros prognósticos entre 0 grupo que sobreviveu $(n=44)$ e aquele que evoluíu para 0 óbito $(n=8)$ está na Tabela 4. Foi observada uma tendência estatística à significância $(p=0,07)$ quando da análise do conjunto das infecções bacterianas, enquanto a análise dos processos infecciosos mais relevantes ( infecção pulmonar e peritonite bacteriana espontânea) mostrou-se significante $(\mathrm{p}=0,004)$ A encefalopatia hepática e níveis de bilirrubinas totais $>20 \mathrm{mg} \%$ também foram mais freqüentes no grupo que evoluiu para 0 óbito. Por outro lado, níveis de albumina $<2 \mathrm{~g} \%$ e níveis de creatinina $>3 g \%$ não alcançaram significância estatística.

\section{DISCUSSÃ0}

A prevalência de hepatite alcóolica em 7,5\% de pacientes hospitalizados devido doença hepática é relevante. Outros autores apresentam porcentagens que variam de 7 a 13\%, dependendo das características da população estudada ${ }^{511}$.

A caracterização anatomopatológica da doença através da realização de biópsia hepática em 73,1\% dos casos possibilitou a inclusão de casos menos graves, na fase pré-cirrótica, embora a maioria dos pacientes fosse constituída por cirróticos.

0 predomínio do sexo masculino é uma constante na doença hepática alcoólica, apesar da maior sensibilidade da mulher, que desenvolve doença com ingestão diária menor de álcool. Aceita-se atualmente que doses $>20 \mathrm{~g}$ de álcool puro por dia sejam suficientes para causar dano hepático no sexo feminino ${ }^{15}$. Em trabalhos anteriores, com população do mesmo hospital, verificamos que a idade media dos indivíduos com cirrose situa-se ao redor dos 50 anos ${ }^{18}$. Como a hepatite alcóolica, teoricamente, é etapa anterior ao pleno desenvolvimento da cirrose, parece-nos razoável que a media de idade encontrada seja 10 anos mais jovem do que o grupo controle de cirróticos do mesmo hospital. Todavia, constatamos extremos de 19 a 69 anos, ou seja todos os adultos que ingerem álcool em doses acima do aceitável estão sujeitos a desenvolver a doença. A ingestão alcóolica desta

Tabela 3 - Avaliação semi-quantitativa das alterações em exames laboratoriais em 52 pacientes com hepatite alcoólica.

\begin{tabular}{|c|c|c|c|c|c|c|c|c|}
\hline \multirow[t]{3}{*}{ Exame } & \multicolumn{8}{|c|}{ Alteração } \\
\hline & \multicolumn{2}{|c|}{ normal } & \multicolumn{2}{|c|}{ discreta } & \multicolumn{2}{|c|}{ moderada } & \multicolumn{2}{|c|}{ intensa } \\
\hline & $\mathrm{n}$ & $\%$ & $\mathrm{n}$ & $\%$ & $\mathrm{n}$ & $\%$ & $\mathrm{n}$ & $\%$ \\
\hline \multirow[t]{2}{*}{ Leucócitos totais ( $\mathrm{n} / \mathrm{por} \mathrm{mm}^{3}$ ) } & 23 & 44,2 & 15 & 28,8 & 11 & 21,1 & 3 & 5,7 \\
\hline & \multicolumn{4}{|c|}{$(5.000-10.000)(>10.000-15.000)$} & \multicolumn{2}{|c|}{$(>15.000-30.000)$} & \multicolumn{2}{|c|}{$(>30.000)$} \\
\hline \multirow[t]{2}{*}{ Gamaglutamil transferase ( GGT) (UI) } & 4 & 7,7 & 27 & 51,9 & 15 & 28,8 & 4 & 7,7 \\
\hline & \multicolumn{2}{|c|}{ (até 63) } & \multicolumn{2}{|c|}{$(64-400)$} & \multicolumn{2}{|c|}{$(401-1.200)$} & \multicolumn{2}{|c|}{$(>1.200)$} \\
\hline \multirow[t]{2}{*}{ Bilirrubina total ( mg\%) } & 6 & 11,5 & 32 & 61,5 & 9 & 17,3 & 5 & 9,6 \\
\hline & \multicolumn{2}{|c|}{ (até 1) } & \multicolumn{2}{|c|}{$(>1-10)$} & \multicolumn{2}{|c|}{$(>10-20)$} & \multicolumn{2}{|c|}{$(>20)$} \\
\hline \multirow[t]{2}{*}{ Tempo de protrombina (\%) } & 31 & 59,6 & 7 & 13,5 & 11 & 21,1 & & 35,7 \\
\hline & \multicolumn{2}{|c|}{$(76-100 \%)$} & \multicolumn{2}{|c|}{$(51-75 \%)$} & \multicolumn{2}{|c|}{$(26-50 \%)$} & \multicolumn{2}{|c|}{$(<25 \%)$} \\
\hline \multirow[t]{2}{*}{ Albumina sérica ( g\%) } & 13 & 25 & 21 & 40,4 & 13 & 25 & 5 & 9,6 \\
\hline & \multicolumn{2}{|c|}{$(>3,5)$} & \multicolumn{2}{|c|}{$(2,5-3,5)$} & \multicolumn{2}{|c|}{$(2,0-2,5)$} & \multicolumn{2}{|c|}{$(<2)$} \\
\hline
\end{tabular}


Tabela 4 - Avaliação comparativa dos fatores de mau prognóstico em hepatite alcoólica

\begin{tabular}{|c|c|c|c|c|c|}
\hline \multirow[t]{2}{*}{ Complicações } & & \multirow[b]{2}{*}{$\operatorname{casos}\left(n^{0}\right)$} & \multicolumn{2}{|c|}{ óbitos $\left(\mathrm{n}^{0}\right)$} & \multirow[b]{2}{*}{ "p" } \\
\hline & & & sim & não & \\
\hline \multirow[t]{2}{*}{ Encefalopatia hepática } & Sim & 5 & 4 & 1 & 0.0120 \\
\hline & Năo & 47 & 4 & 43 & \\
\hline \multirow[t]{2}{*}{ Bilirrubinas totais > 20mg\% } & Sim & 5 & 4 & 1 & 0,0120 \\
\hline & Nẵo & 47 & 4 & 43 & \\
\hline \multirow[t]{2}{*}{ Albumina sérica < 2g\% } & Sim & 5 & 2 & 3 & 0,1642 \\
\hline & Nắo & 47 & 6 & 41 & \\
\hline \multirow[t]{2}{*}{ Creatinina sérica > 3mg\% } & Sim & 4 & 3 & 1 & 0,0936 \\
\hline & Nắo & 48 & 5 & 43 & \\
\hline \multirow[t]{2}{*}{ Infecção bacteriana } & Sim & 11 & 5 & 6 & 0,0706 \\
\hline & Nẵo & 41 & 6 & 35 & \\
\hline \multirow[t]{2}{*}{ *PBE/ infecção pulmonar } & Sim & 7 & 5 & 2 & 0,0040 \\
\hline & Năo & 45 & 2 & 43 & \\
\hline
\end{tabular}

* PBE = peritonite bacteriana espontânea

casuística foi semelhante àquela relatada entre nós, para os pacientes com cirrose ${ }^{19}$.

Ao estudarmos esta população de pacientes hospitalizados com hepatite alcóolica verificamos uma grande riqueza de sintomas e sinais (Tabela 2), que podem falsear a noção diagnóstica da hepatite alcoólica. É importante ressaltarmos a existência de outros estudos, particularmente baseados em inquéritos ambulatoriais seguidos de biopsia hepática, nos quais o diagnóstico histopatológico praticamente não se acompanha de sintomas clínicos. De qualquer forma, esta era nossa população de interesse, já que buscávamos exatamente as formas mais graves para avaliar índices prognósticos.

Uma observação interessante é a constatação de que a doença hepática alcoólica altera 0 sistema imunológico levando a uma situação de menor reatividade ( hipoérgicos) evidenciada pela baixa freqüência de hipertermia ${ }^{4}$. 0 surgimento de febre é referido como um dos possíveis sintomas de hepatite alcóolica. Além disso, 0 diagnóstico de infecções bacterianas, que surgiram como complicação em 11 pacientes também poderiam acompanhar-se de febre. Entretanto, ela esteve presente em apenas 8 casos.

As alterações dos exames laboratoriais ajudam o diagnóstico, sendo necessária uma análise conjunta, já que nenhum deles tem especificidade de $100 \%$. Para cada um dos parâmetros analisados foi possível caracterizar uma porcentagem ora pequena ora grande de pacientes com valores dentro da faixa de normalidade. A avaliação semiquantitativa mostrou níveis de leucócitos acima de $30.000 / \mathrm{mm}^{3} \mathrm{em} 3$ pacientes, de GGT > 1.200 unidades em 4 casos e de tempo de protrombina $<25 \%$ em 3 deles. (Tabela 3 ).

Já é clássico em hepatite alcóolica que os pacientes com bilirrubinas totais $>20 \mathrm{mg} \%$ tem pior prognostic ${ }^{9}$. Quando a hiperbilirrubinemia se associa a acentuadas alterações da coagulação sanguínea, expressas pelo alargamento do tempo de protrombina, é possível aplicar a fórmula de Maddrey9. Segundo esses autores um índice superior a 32 pontos justifica a utilização terapêutica de corticosteróides, desde que não haja infecção bacteriana concomitante. Nesta casuística, 4 dos 52 pacientes foram tratados com prednizona durante a internação e 3 deles sobreviveram.
Nosso índice de mortalidade $(15,4 \%)$ nesta casuística de hepatite alcóolica está de acordo com a literatura, considerada a inclusão de pacientes com a doença em suas diferentes fases, desde formas leves até as mais graves, correspondendo ao universo total dos pacientes internados naquele período ${ }^{5}$. Se fossemos analisar exclusivamente os casos mais graves, nos quais ocorre associação dos diferentes fatores de pior prognóstico, provavelmente teríamos um percentual maior de mortalidade.

Nos 11 pacientes em que foi diagnosticada infecção bacteriana, chama a atenção 0 contraste com os achados da cirrose. Nesta ultima, os nossos trabalhos, corroborados por outros da literatura, demonstram que peritonite bacteriana espontânea e infecção urinária são as mais freqüentes ${ }^{40}$. Embora presentes, nesta casuística a infecção pulmonar foi predominante. Em trabalho recente, demonstramos que os índices de mortalidade guardam relação direta com o órgão ou sistema acometido pela infecção, nos casos de cirrose ${ }^{20}$. Assim, enquanto a septicemia apresenta os maiores índices de mortalidade (80\%), na infecção pulmonar os índices também são altos (50\%) enquanto nas infecções urinária e dermatológica 0 prognóstico é melhor, com apenas $25 \%$ de mortalidade na cirrose hepática ${ }^{20}$. Os índices de mortalidade da peritonite bacteriana espontânea, devido diagnóstico precoce e sobretudo ao uso empírico imediato de antibióticos eficazes, como as cefalosporinas de segunda e terceira gerações, vêm diminuindo gradativamente desde os anos $1970^{6} 1220$. Nesta casuística, os dois pacientes com peritonite bacteriana espontânea foram a óbito.

Finalmente, resta comentar o principal achado do nosso estudo. Constatamos que efetivamente, assim como na cirrose, 0 surgimento de infecções bacterianas na hepatite alcóolica é fator de pior prognóstico. Aimportância prática desta conclusão é a de buscar ativamente o diagnóstico precoce de infecção bacteriana quando da suspeita clinica de hepatite alcóolica, já que 0 tratamento empírico precoce pode modificar a historia natural da infecção, como vem ocorrendo com a peritonite bacteriana espontânea.

A profilaxia das infecções bacterianas é aceitável em casos de hepatite fulminante ${ }^{13}$, assim como durante hemorragia digestiva alta por hipertensão portal ${ }^{16}$. Face os achados do nosso trabalho, consideramos aconselhável recomendar que também na hepatite alcóolica, em sua forma grave, seja realizado sistematicamente tratamento profilático. Novas investigações são aconselháveis com finalidade de confirmar nossos achados e verificar a eficiência de esquemas terapêuticos profiláticos.

\section{REFERÊNCIAS BIBLIOGRÁFICAS}

1. Angulo P. Nonalcoholic fatty liver disease. New England Journal of Medicine 246: 1221-1231, 2002

2. Bernard B, Grange JD, Khac EN, Amiot X, Opolon P, Poynard T. Antibiotic prophylaxis for the prevention of bacterial infections in cirrhotic patients with gastrointestinal bleeding: a meta-analysis. Hepatology 29: 1655-1661, 1999.

3. Borzio M, Salerno F, Piantoni L, Cazzaniga M, Angeli P, Bissoli F, Boccia S, Colloredo-Mels G, Corigliano P, Fornaciari G, Marenco G, Pistara R, Salvagnini M, Sangiovanni A. Bacterial infection in patients with advanced 
cirrhosis: a multicentre prospective study. Digestive and Liver Disease 33: 41-48, 2001

4. Caly WR, Strauss E. A prospective study of bacterial infections in patients with cirrhosis. Journal of Hepatology 18: 353-358, 1993.

5. Chedid A, Mendenhall CL, Gartside P,French SW, Chen T, Rabin L. Prognostic factors in alcoholic liver disease. American Journal of Gastroenterology 86: 210-216, 1991.

6. Fernandez J, Navasa M, Gomez J, Colmenero J, Vila J, Arroyo V, Rodes J. Bacterial infections in cirrhosis: epidemiological changes with invasive procedures and norfloxacine prophylaxis. Hepatology 35: 140-148, 2002.

7. Gregory DH, Levi DF. The clinical-pathological spectrum of alcoholic hepatitis. American Journal Digestive Disease 17:479-488, 1972.

8. Hall PM. Pathological spectrum of alcoholic liver disease. In: Hall P (ed) Alcoholic liver disease - pathology and pathogenesis. John Wiley and Sons, New York p. 41-68, 1995.

9. Maddrey WC, Boitnott JK, Bedine MS, Weber FL Jr, Mezey E, White RI Jr. Corticosteroid therapy of alcoholic hepatitis. Gastroenterology 75: 193199, 1978.

10. Navasa M, Rimola A, Rodés J. Bacterial Infections in Liver Disease. Seminars in Liver Disease 17: 323-333, 1997.

11. Ohnishi K, Okuda K Epidemiology of alcoholic liver disease in Japan. In: Hall P (ed) Alcoholic liver disease - pathology and pathogenesis. John Wiley and Sons, New York p. 167-86, 1995.

12. RicartE, Soriano G, Novella M, Ortiz J, Sabat M, Kolle L, Sola-Vera J, Minana J, Dedeu JM, Gómez C, Barrio JL, Guarner C. Amoxicillin-clavulanic acid versus cefotaxime in the therapy of bacterial infections in cirrhotic patients. Journal of Hepatology 32: 596-602, 2000.
13. Rolando N, Harvey F, Brahm J, Philpott-Howard J, Alexander G, Gimson A, Casewell M, Fagan E, Williams R. Prospective Study of Bacterial Infection in Acute Liver Failure: An Analysis of Fifty Patients. Hepatology 11: 49-53, 1990.

14. Runyon BA. Spontaneous Bacterial Peritonitis: An Explosion of Information (Editorial). Hepatology 8: 171-175, 1988.

15. Schenker S. Medical consequences of alcohol abuse: is gender a factor? Alcoholism, Clinical Experimental Research 21: 179-181, 1997.

16. Soares-Weise K, Brezis M, Tur-Kaspa R, Leibovici L. Antibiotic prophylaxis for cirrhotic patients with gastrointestinal bleeding. Cochrane Database System Review (2): CD002907, 2002.

17. Strauss E, Caly WR Peritonite bacteriana espontânea. Revista da Sociedade Brasileira de Medicina Tropical 36: 711-717, 2003.

18. Strauss E, Lacet CMC, Maffei RA Jr, Silva EC, Fukushima J, Gayotto LCC. Etiologia e apresentacãa da cirrose hepática em São Paulo: análise de 200 casos. Gastroenterologia Endoscopia Digestiva 7: 119-123, 1988.

19. Strauss E, Nemoto TC, Borges GT, Cunha AA, Freitas GC, Parrado MAR, Abud RM, Ribeiro MFGS. Alcoolismo crônico: avaliação clinico-epidemiológica de 300 casos. Gastroenterologia Endoscopia Digestiva 17: S75, 1998.

20. Strauss E, Ribeiro MFGS Bacterial infection associated with hepatic encephalopathy: prevalence and outcome. Annals of Hepatology 2: 41-45, 2003.

21. Toledo CA, Flores CW, Sáenz MF, Jimenez P, Tejero A, Ibarra H, Leon J, Arce M. Infecciones Bacterianas en la cirrosis hepatica. Revista Medica de Chile 122: 788-794, 1994.

22. Xiol X, Castellvi JM, Guardiola J, Sese F, Castellote J, Perello A, Cervantes $\mathrm{X}$, Iborra MJ. Spontaneous bacterial empyema in cirrhotic patients: a prospective study. Hepatology 23: 719-733, 1996. 